\title{
PERFORMANCE ANALYSIS OF ALTERNATIVE COVERINGS FOR COOLING TOWERS IN BRAZILIAN CAPITALS THROUGH NUMERICAL MODELING
}

\author{
A. C. C. Tomás ${ }^{\mathrm{a}}$, \\ P. H. Souza ${ }^{b}$, \\ and A. R. M. Primoc \\ ${ }^{\mathrm{a}}$ Instituto Federal de Educação Ciência e \\ Tecnologia de Pernambuco \\ Departamento de Mecânica \\ Campus Recife \\ Bairro Cidade Universitária \\ CEP. 50740-540, Recife, Pernambuco, Brasil \\ andrezzaoliveira@recife.ifpe.edu.br \\ ${ }^{b}$ Universiade Federal de Pernambuco \\ Departamento de Engenharia Mecânica \\ Bairro Cidade Universitária \\ CEP. 50670-901, Recife, Pernambuco, Brasil \\ phsouza8@msn.com \\ ${ }^{\mathrm{c}}$ Universiade Federal de Pernambuco \\ Departamento de Engenharia Mecânica \\ Bairro Cidade Universitária \\ CEP. 50670-901, Recife, Pernambuco, Brasil \\ Received: September 30, 2016 \\ Revised: October 27, 2016 \\ Accepted: March 16, 2017
}

\section{ABSTRACT}

A cooling tower is a heat removal device used to transfer waste heat to the atmosphere process. Today, commercial cooling towers use plastic coverings, specially developed for this application. It is known that alternative coverings have been an increasingly viable solution thanks to its performance and cost. The purpose of this study was to evaluate, through numerical simulation, the performance of different alternative coverings under different climatic conditions. Therefore, we used, as reference, the climate of the state capitals and their respective geographic regions. The performance of these coverings was evaluated through observation of three parameters: effectiveness, approach and cooling. The main input data used by the software EES (Engineering Equation Solver) for the calculation of evaluation parameters were: experimental NUT of each covering, average local temperature, local air pressure and relative humidity. The flow of water and air were set at $0.33 \mathrm{~L} / \mathrm{s}$ and $170 \mathrm{~L} / \mathrm{s}$, respectively. We concluded that the air inlet temperature and relative humidity at each location greatly influence the performance of the coverings. The alternative covering that showed the best results was the "cross-fiber and neck", with an efficiency about 35\% lower than the industrial covering. The Brazilian capital city with the best performances for alternative coverings was Palmas (TO). This is due to the very low relative humidity found in the city in the summer. Air humidity is also responsible for the poor performance of coverings in the capitals of the North. In general, the region with the best performance was the South, due to the characteristics of the sub-tropical climate. Regions that had the worst results were North / Northeast because of the weather that combines high temperatures with high / moderate humidity, respectively. Thus, the study of climate conditions is indispensable for the operation prevision of a cooling tower. Alternative coverings will be viable depending on the location.

Keywords: cooling tower, alternative coverings, Brazilian capitals, numerical simulation, NTU

\section{NOMENCLATURE}

$c_{p_{u}} \quad$ specific heat of moist air, J.kg-1.K-1

$h_{i}$

enthalpy of saturated air at the water temperature, J.kg-1

$\mathrm{H}$ enthalpy (in (i) and out (o) of the control volume), $\mathrm{J}$

Lef fator de Lewis

$\dot{m}_{a} \quad$ mass flow rate of air, kg.s -1

$\dot{m}_{w} \quad$ mass flow rate of water, $\mathrm{kg} . \mathrm{s}-1$

NTU numbers of Transfer Units, kg.s-1

n number sections

$\dot{Q}$ heat, $\mathrm{W}$

$\dot{Q}_{S} \quad$ The sensible heat flow, $\mathrm{W}$

$\dot{W} \quad$ work, $\mathrm{W}$

$\alpha_{c}$ coefficient of heat transfer by convection, W.m-2. K-1

\section{$\varepsilon \quad$ Effectiveness, \%}

Subscripts
ar air
ag water

\section{INTRODUCTION}

An evaporative cooling tower is a device used to remove heat produced in a system. The heat is transferred to a water circuit, where the heated water is sprayed on top of the cooling tower and flows through a filler, losing heat, returning much cooler, in order to receive heat again. The fill enhances the heat exchange by increasing the contact time of the water with air. Ambient air is blown through this structure, in counter or cross current to the circulating water, causing its cooling, by evaporation.

Although there are many studies on cooling towers, few include or emphasize the selection of filling materials. The ideal filler for a cooling tower should present low cost and maximize heat and mass 
transfer and also maintaining uniform the water and air flow. Industrial fillers seek to achieve this. They are made of a plastic material specially developed for this application.

Alternative fillers are made of available materials, ranging from local fibers to recyclable materials such as PET bottles. The challenge of using this source is to find the optimal configuration for each material, which favors heat and mass transfer, without increasing the pressure drop in the tower. PET bottles have a long decomposition process when discarded into the environment. Therefore the utilization of recycled materials in cooling towers also represents an additional solution to an environmental problem.

The technical literature on alternative fillers is very scarce, as well as published studies comparing the performance of these fillers in different weather conditions. Al Sulaiman 2002, tested some local fibers as alternative filler materials. Barros, 2005, created a test tunnel for local fibers. Costa, 2006 and Oliveira, 2009 pointed out some alternative materials for cooling towers. Oliveira, 2012, determined experimentally new arrangements, with some alternative materials as coconut fiber and bottlenecks of PET bottles.

The aim of this study is to test numerically the feasibility of new fillers for cooling towers in different weather conditions, for each one of the Brazilians capitals. Figure 1 to 6 show the arrangements previously studied by Oliveira, 2012.

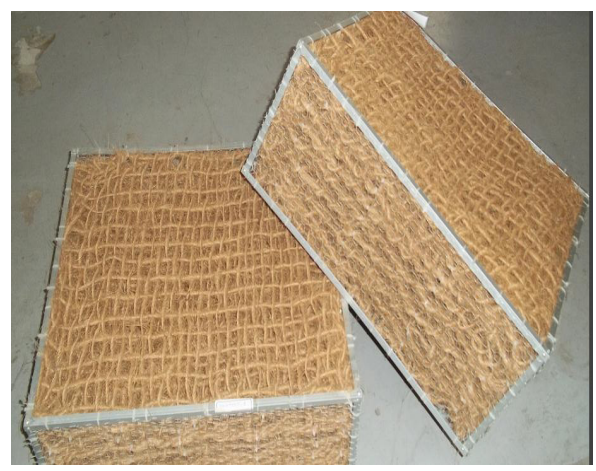

Figure 1. Crossed Fiber.

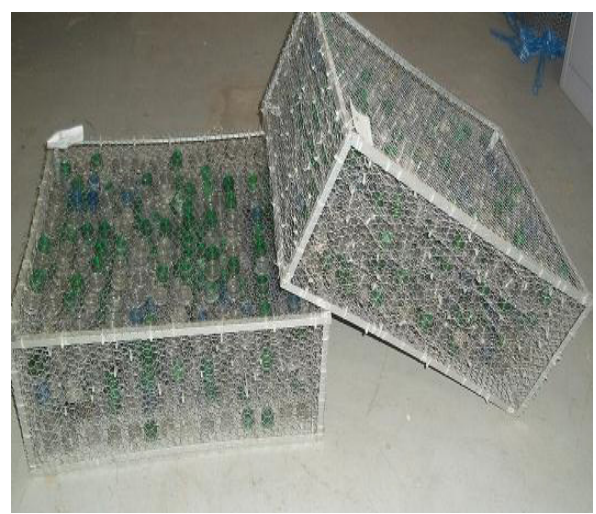

Figure 2. Assembled Bottle necks.

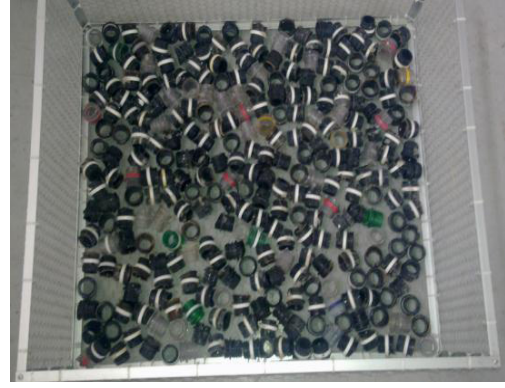

Figure 3. Bottle necks.

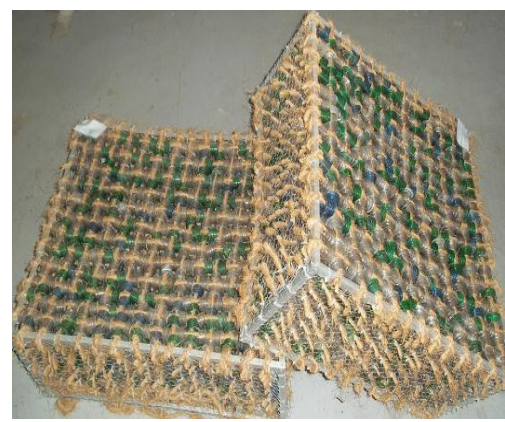

Figure 4. Crossed Fiber and Bottle necks.

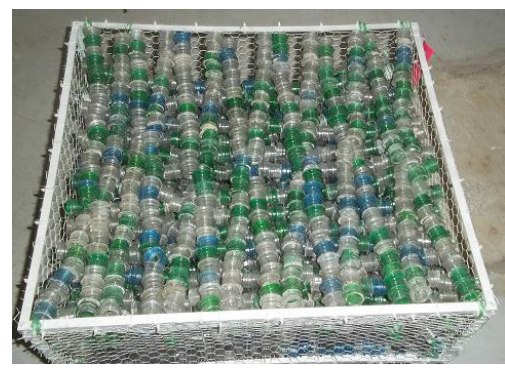

Figure 5. PET wire and Bottle necks.

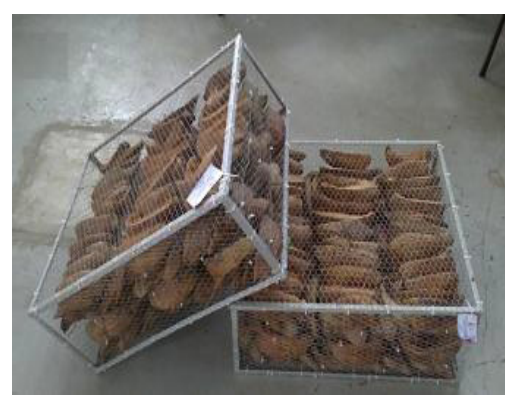

Figure 6. Coconut Shell.

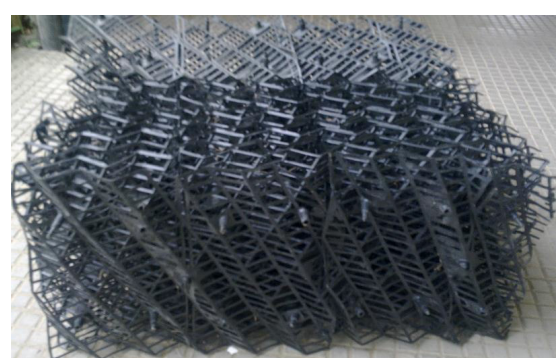

Figure 7. Industrial Filler chosen for comparison. 
The performance of these fillers was compared to the performance of an industrial filler (figure 7), for Brazilian capital cities and Brazilian regions.

\section{MATHEMATICAL MODELING OF COUNTERCURRENT COOLING TOWER}

Through mathematical modeling of countercurrent cooling tower it was possible to evaluate the relationship of the tower outlet water temperature with the wet bulb temperature of the intake air through the NUT, number of transfer units; This model was used by Oliveira (2009).

In countercurrent towers, while the water remains on a downward direction, the air goes in ascending direction and due to this contact between air and water, moisture in the air increases. The increase in humidity is due to the fact that there are mass transfer because of the evaporation of warm water. By observing Fig. 8 a flow of water mass flow rate is visualized, $\dot{m}_{a g}$, at the temperature T1, which must be cooled to the temperature T2. Also the mass flow of air $\dot{m}_{a r}$ circulating through the tower can be observed. The evaporated water mass flow is considered negligible compared to the total flow of the process water.

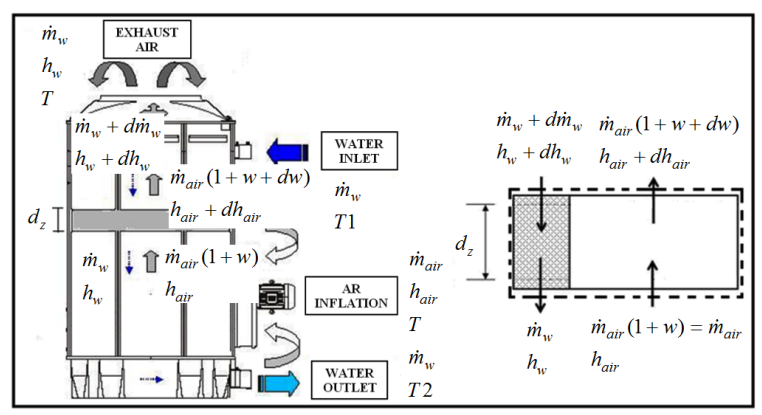

Figure 8. Filling volume control in countercurrent.

Making an energy balance in the volume control shown in Figure F.8 we have: By 1st Law:

$\frac{d E}{d t}=\Sigma H_{e}-\Sigma H_{s}+\Sigma \dot{Q}-\Sigma \dot{W}$

Considering that the tower operates on a permanent basis, $\frac{d E}{d t}=0$. As there is no work performed by the tower and considering it adiabatic, we have:

$$
\begin{aligned}
& \Sigma H_{e}=\Sigma H_{s} \\
& 0=\dot{m}_{a r} h_{a r}+\left(\dot{m}_{a g}+d \dot{m}_{a g}\right)\left(h_{a g}+d h_{a g}\right)-\dot{m}_{a g} h_{a g}-\dot{m}_{a r}\left(h_{a r}+d h_{a r}\right)
\end{aligned}
$$

Simplifying and rearranging gives:

$$
\dot{m}_{a r} d h_{a r}-\dot{m}_{a g} d h_{a g}-h_{a g} d \dot{m}_{a g}=0
$$

As the loss of water by evaporation will not be considered, the total heat flow removed from the water is given by:

$$
\delta \dot{Q}=\dot{m}_{a r} d h_{a r}=\dot{m}_{a g} d h_{a g}
$$

This analysis is done only by the energy balance and needs to be supplemented with the expression below to consider the effects of heat and mass transfer, where:

$$
\delta \dot{Q}=\frac{\alpha_{c} d A}{c_{p_{u}}}\left(h_{i}-h_{a r}\right)=\dot{m}_{a r} d h_{a r}=\dot{m}_{a g} d h_{a g}
$$

According to the adopted simplification, $d h=c_{p} d T$ gives:

$$
\delta \dot{Q}=\frac{\alpha_{c} d A}{c_{p_{u}}}\left(h_{i}-h_{a r}\right)=\dot{m}_{a g} c_{p_{a g}} d T
$$

Integrating the equation above, gives:

$$
\dot{m}_{a g} \int_{T_{1}}^{T_{2}} \frac{c_{p_{a g}} d T}{\left(h_{i}-h_{a r}\right)}=\int_{0}^{A} \frac{\alpha_{c} d A}{c_{p_{u}}}=\frac{\alpha_{c} A}{c_{p_{u}}}
$$

The expression $\frac{\alpha_{c} A}{c_{p_{u}}}$ is defined as NUT, number of transference units, in $\mathrm{kg} / \mathrm{s}$, so:

$$
N U T=\dot{m}_{a g} \int_{T_{1}}^{T_{2}} \frac{c_{p_{a g}} d T}{\left(h_{i}-h_{a r}\right)}
$$

The NUT depends on certain variables such as: the geometry of the air-water contact, the regime of velocity, viscosity, or flow characteristics, implicit within the heat transfer coefficient, $\alpha_{c}$ is approximately constant over a given cooling tower. A high NUT signals that the temperature of the tower leaving water approaches the wet bulb temperature of the supply air (Simões-Moreira, 1999). The performance curves for each tested filler can be obtained with the NUT, obtained from experimental data (Mello, 2008).

It can be found, in several works, a dimensionless number called number Merkel, where the NUT derives, defined by NUT divided by water flow. (Oliveira, 2012).

\section{NUMERICAL MODELINGIN EES}

The NUT was calculated for each filling of the cooling tower from experimental data, as shown in 
Table A.1. Being the NUT known, situations of different test conditions to predict the tower operating conditions can be simulated. The calculations are made by an iterative procedure. These calculations are made using the simulation software "Engineering Equation Solver" (EES), for a resolution of a system of equations which contains thermal properties of moist air. In this study, the NUT is no longer a variable and takes a set amount for each filling. The NUT used for numerical simulation is the average NUT which is the average of the three NUT values found for each filler present in Table 1.

Table 1. NUT for each filling and different temperatures, with air flow $0.17 \mathrm{~m}^{3} / \mathrm{s}$.

\begin{tabular}{|l|c|c|c|}
\hline Water/Air & & $\mathbf{1 . 2} \mathbf{~ m 3 / h}$ & $\mathbf{0 . 1 7} \mathbf{~ m 3 / s}$ \\
\hline Temperature $\left({ }^{\circ} \mathrm{C}\right)$ & $\mathbf{3 4}$ & $\mathbf{3 7}$ & $\mathbf{4 0}$ \\
\hline INDUSTRIAL & 0.1366 & 0.1341 & 0.1277 \\
\hline ASSEMBLED BOTTLE NECKS & 0.092 & 0.0813 & 0.08165 \\
\hline CROSSED FIBER & 0.05704 & 0.0641 & 0.05722 \\
\hline FIBER AND BOTTLE NECK & 0.03987 & 0.04344 & 0.04017 \\
\hline PET WIRE AND BOTTLE NECK & 0.09295 & 0.08941 & 0.08498 \\
\hline BOTTLE NECK & 0.08195 & 0.07807 & 0.07096 \\
\hline CROSSED FIBER AND BOTTLE NECK & 0.08624 & 0.0829 & 0.07782 \\
\hline COCONUT SHELL & 0.07231 & 0.07504 & 0.0785 \\
\hline
\end{tabular}

SOURCE: OLIVEIRA, 2012

The variable is fixed "NUT exp" according to the average found for each filling NUT (Table 1) and varies the experimental data entry, such as the local atmospheric pressure and air inlet temperature ranging from capital to capital.

First, they collected weather data (average summer temperature and average relative humidity) on all Brazilian capitals through the website of the National Institute of Meteorology (http://www.inmet.gov.br/).

According to the Weather Forecasting and Climate Studies Center (CPTEC), summer in Brazil is between the months of December and March. Theoretically, summer is the time of year where higher temperatures are reached and this would be a good time to analyze the cooling tower efficiency. Therefore, the collected climate data refer to the summer period in the country.

\section{PRESENTATION AND DISCUSSION OF RESULTS}

For this work, a water flow of $1.2 \mathrm{~m}^{3} / \mathrm{h}$ and an air flow rate of $0.17 \mathrm{~m}^{3} / \mathrm{s}$ have been fixed as they were varied and the following input parameters was set: average local temperature, local air pressure and relative humidity. It was possible to numerically calculate the parameters which are desired to be observed: effectiveness, approach and cooling.

Figures 9 to 11 show a comparison between the Industrial filler and the "Crossed fiber and bottle necks" filler and between the Industrial filler and "Crossed fiber". All the alternative fillers, except the "Crossed fiber" filler, have shown similar results. Because of the lack of space and a matter of information clarity, we decided to present only the best and the worst results for the alternative fillers. It is known that all the other fillers have presented results pretty close to the "Crossed fiber and Bottle necks" filler. Therefore, the results below are for only these three fillers:

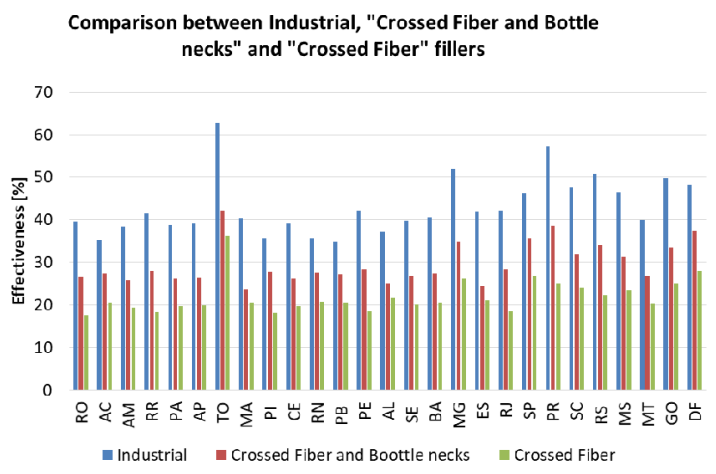

Figure 9. Comparison of Effectiveness.

Comparison between Industrial, "Crossed Fiber and Bottle necks" and "Crossed Fiber" fillers

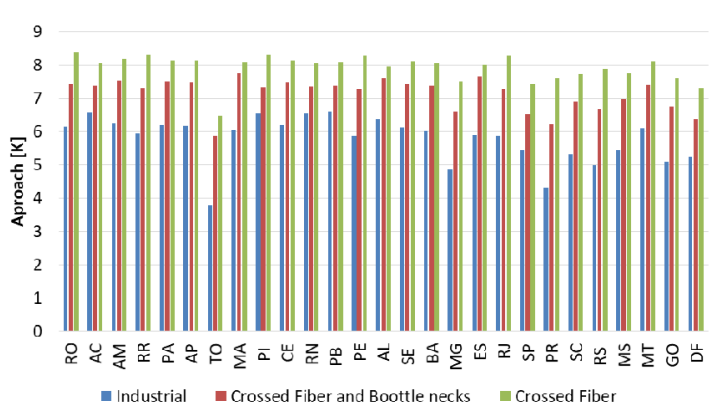

Figure 10. Comparison of Approach.

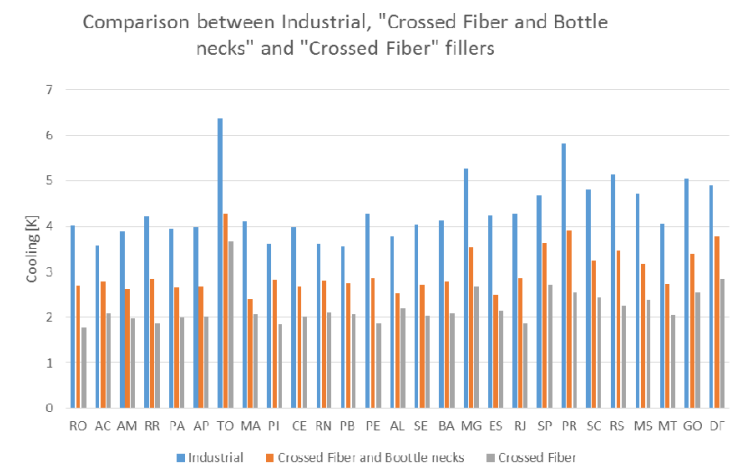

Figure 11. Comparison of Cooling.

It is understood, through numerical simulation, that the industrial filler presented good parameters: effectiveness, approach and cooling. A $6.37 \mathrm{~K}$ cooling has been reported in Palmas (TO) in the summer. The worst result was for Joao Pessoa (PB) which showed a cooling rate of only $3.55 \mathrm{~K}$. Palmas (TO) still shows a $62.77 \%$ effectiveness and a 3,779 $\mathrm{K}$ approach. Meanwhile, João Pessoa (PB) shows effectiveness of $35.02 \%$ and a $6.595 \mathrm{~K}$ approach. The performance of the industrial filler served as a reference for comparison with alternative fillings, 
bottle neck and coconut shell. The industrial filling should show the best results, as it was indeed observed.

The alternative fillers effectiveness must be close to the Industrial filler effectiveness. The cooling range must be wide and the approach must be small. The graphics below behaved as expected.

The figures 12 to 16 represent the effectiveness, the approach and the cooling range for the Brazilian capitals.

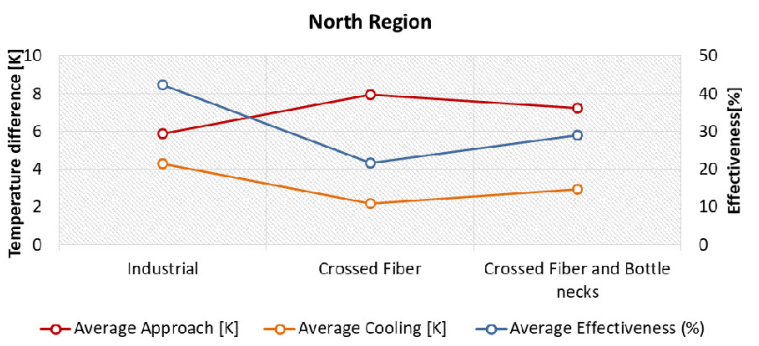

Figure 12. Graph for the North.

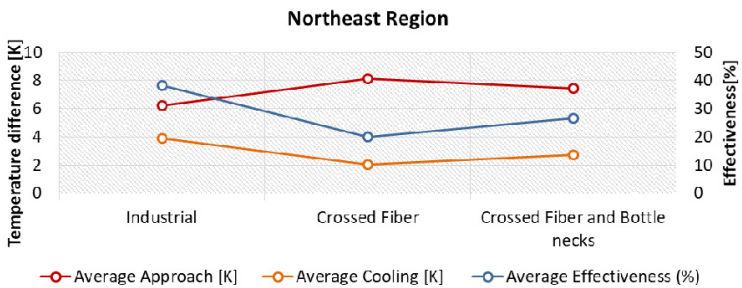

Figure 13. Graph for the Northeast.

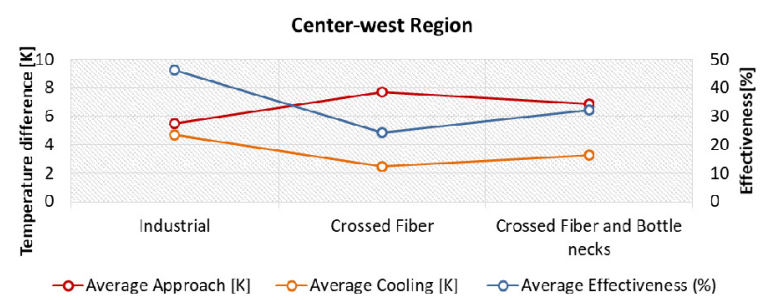

Figure 14. Graph for the Center-West.

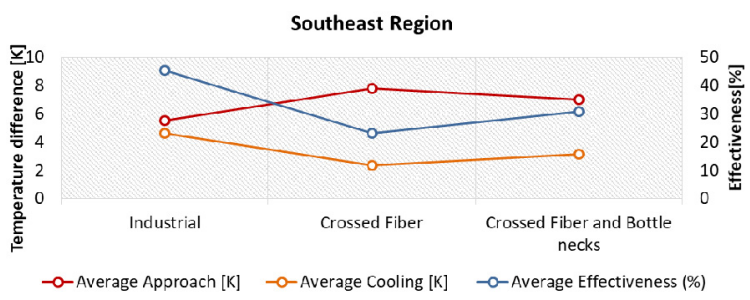

Figure 15. Graph for the Southeast.

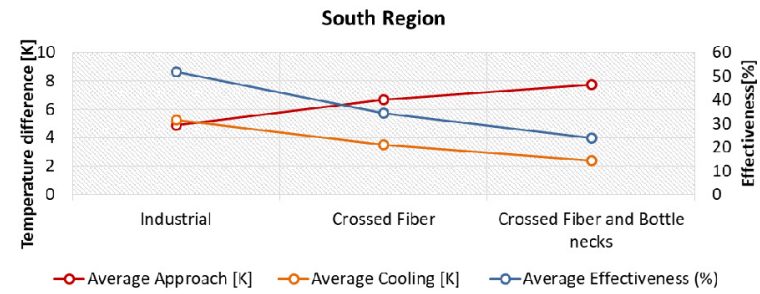

Figure 16. Graph for the South.
Comparing the figures 12 to 16 , we realize that the South region shows the best results.

\section{CONCLUSIONS}

The results from the numerical simulations were consistent with results from studies found in the literature. Alternative fillers efficiency was about $37-$ $40 \%$ lower than in the industrial filling, which is the reference.

Due to the fact that most Brazilian capital cities are on the coast, the local atmospheric pressure did not influence the results.

It has been concluded that Palmas (TO) showed the best performance among the capitals due to its extremely low relative humidity. Because of the humidity, many of the capitals of the North region had the worst results. We conclude that a high relative humidity compromises the efficient functioning of the cooling tower.

Regarding to regions, the conclusion is that, in general, the South has the best performance among the fillers due to the climatic characteristics of the region that combine low temperatures with moderate humidity.

Similarly, the North / Northeast regions have the worst results due to climatic conditions which combine high temperatures with high / moderate humidity.

We conclude that the study of climate conditions is indispensable for predicting the operation of a cooling tower and alternative fillers are increasingly viable depending on the location and availability, and may add value to materials that are actually harmful to environment, such as coconut shell and PET bottle.

\section{REFERENCES}

Barros, R. R., 2005, Bancada Experimental para teste de enchimentos usados em resfriadores evaporativos, Master Thesys, Programa de PósGraduação em Engenharia Mecânica - UFPE, Recife, PE. (in Portuguese)

Costa, J. A. P. D., 2006, Utilização de Materiais Alternativos como Enchimento de Torres de Resfriamento, Master Thesys, Programa de PósGraduação em Engenharia Mecânica - UFPE, Recife, PE. (in Portuguese)

Oliveira, A. C. C. T., 2009, Análise da Utilização de Gargalos e Fios de Garrafa PET como Enchimento de Torres de Resfriamento, Master Thesys, Programa de Pós-Graduação em Engenharia Mecânica - UFPE, Recife, PE. (in Portuguese)

Oliveira, A. C. C.T., 2012, Estudo de Materiais Alternativos para o Enchimento de Torres de Resfriamento, Doctoral Thesys, Programa de PósGraduação em Engenharia Mecânica - UFPE, Recife, PE. (in Portuguese) 